\title{
Evaluating Primary Health Care Performance from User Perspective in China: Review of Survey Instruments and Implementation Issues
}

\author{
Wenhua Wang ${ }^{1}$, Jeannie Haggerty ${ }^{1}$, Ekaterina (Katya) Loban ${ }^{1}$ and Xiaoyun Liu ${ }^{2, *}$ \\ 1 Department of Family Medicine, McGill University, Montreal, QC H3T 1M5, Canada; \\ wenhua.wang@mail.mcgill.ca (W.W.); Jeannie.haggerty@mcgill.ca (J.H.); \\ ekaterina.loban@mail.mcgill.ca (E.(K.)L.) \\ 2 China Center for Health Development Studies, Peking University, Beijing 100191, China \\ * Correspondence: xiaoyunliu@pku.edu.cn; Tel.: +86-10-82805697
}

Received: 26 January 2019; Accepted: 11 March 2019; Published: 14 March 2019

\begin{abstract}
This review aims to summarize the progress of patient evaluation studies focusing on primary health care (PHC) in China, specifically in relation to survey instruments and implementation issues. Eligible studies published in English or Chinese were obtained through online searches of PubMed and China National Knowledge Infrastructure. A descriptive reporting approach was used due to variations in the measurements and administration methods between studies. A total of 471 articles were identified and of these articles; of those 91 full-text articles were included in the final analysis. Most studies used author-developed measurements with five-point Likert response scales and many used the Chinese translations of validated tools from other countries. Most instruments assessed the physical environment, medical equipment, clinical competency and convenience aspects of PHC using a satisfaction rating instead of care experience reporting. Many studies did not report the sampling approach, patient recruitment procedures and survey administration modes. The patient exit survey was the most commonly used survey implementation method. The focus on the structural dimensions of PHC, inconsistent wording, categories of response options that use satisfaction rating, and unclear survey implementation processes are common problems in patient evaluation studies of $\mathrm{PHC}$ in China. Further studies are necessary to identify population preferences of PHC in China in order to move towards developing Chinese value-based patient experience measurements.
\end{abstract}

Keywords: primary health care; performance evaluation; user experience; patient survey; China

\section{Introduction}

In China, the primary health care (PHC) system set up in the 1950s has contributed to a dramatic reduction in maternal and infant mortality, a significant improvement in general population health and the development of the Declaration of Alma-Ata in 1978 [1]. However, the market economic reform, which began in 1978, undermined the previously established PHC system [2]. Instead, a hospital-centered fragmented delivery system was developed where health facilities at different levels were encouraged to self-finance through user charges and price mark-ups on medications and procedures. These developments incentivized high technology and low interinstitutional referral, with escalating medical costs, low affordability, public dissatisfaction and a significant disparity between urban and rural areas [3-8].

To address these issues, China launched a national health reform in 2009 with the aim of providing its citizens with essential public health and basic medical services that are safe, effective, accessible and affordable through a strong PHC based health system [9]. Guided by this national strategy, China has made a significant investment in health infrastructure at the PHC level and made significant progress 
in strengthening the primary care workforce. Combined with the impact of expanding social health insurance coverage, that provides a basic public health service package and an essential medicines program, China has witnessed a more equitable access to health care and greater affordability $[1,4]$. To deepen the health reform efforts, China is currently reshaping its tiered health care delivery system in accordance with the World Health Organization (WHO) Framework on Integrated People-Centered Health Services [10], which calls for health services to be organized around the health needs and preferences of individuals and requires active patient engagement in the care-seeking process [11]. There is growing interest in measuring PHC performance from a patient perspective in order to assess the Chinese reform effectiveness. However, the survey instruments and implementation approaches used vary significantly between studies.

Patient experience has been studied extensively in developed countries. It is recognized as one of the pillars of health care quality alongside clinical effectiveness and patient safety [12]. Patient experience during the service delivery process is also a major determinant of trust in and satisfaction with PHC [13]. Patients are the best evaluators of key aspects of PHC, such as interpersonal communication, shared decision-making, relational continuity, respect, privacy and advocacy [14]. With a positive care experience, patients are more likely to adhere to the recommended prevention methods and treatments, which subsequently results in better clinical and health outcomes $[12,15,16]$. Positive patient experience is also associated with a reduced use of health care resources and lower health care costs $[17,18]$. As an important indicator in health care performance evaluation, patient experience is included in quality improvement programs in developed countries, including the United Kingdom (UK), Australia, Canada and the United States of America (USA) [19].

Some of the widely used patient experience instruments in developed countries include the Primary Care Assessment Survey (PCAS) [20]; the Consumer Assessment of Healthcare Providers and Systems (CAHPS) [21,22]; the World Health Organization Health System Responsiveness Survey [23]; and the Primary Care Assessment Tools (PCAT) [24]. Several lessons have been learned from the development and application of these instruments. First, PHC domains and items should be selected based on health system features and population preferences in a specific context. For example, to adapt PCAS from the USA to the UK, several modifications were made, including rewording some questions, removing questions that are not relevant in the UK and adding domains relating to patient priorities in the UK [25]. Second, the wording of item response scales should reflect the response tendency of the local population. For example, for Canadians, Likert response scales function best and agreement scales are least appreciated [26]. Third, survey administration methods may influence the measurement error. For example, telephone respondents tend to give more positive responses than mail respondents [27].

These lessons provide practical information for patient survey design and implementation in developing countries, including China, where there is growing interest in measuring PHC performance from a user perspective. This literature review aims to summarize the progress and issues with patient evaluation studies of PHC in China in relation to three aspects: the choice of domains and items, the choice of response scales, and survey administration methods. The results will lay a solid foundation for further development of patient experience measurement methods in China.

\section{Methods}

\subsection{Databases and Search Terms}

PubMed and China National Knowledge Infrastructure (CNKI) were searched to identify relevant articles. The PubMed and CNKI searches were conducted in February 2018. The following key search terms and their synonyms were used: China, primary health care, primary care, community health, township health center, village clinic, assessment, evaluation, measurement and patient. An iterative approach was used to identify search terms. The final search strategy can be found in Supplement 1 . Only the publications in English and Chinese were retained. No time limit was imposed. 


\subsection{Selection of Studies for Inclusion}

A total of 169 articles in English and 302 articles in Chinese were identified. The following inclusion criteria were used: (1) the study is part of original research in China; (2) the study design is a patient survey; (3) the study reports the information on the measurement and administration of patient surveys. The screening process was conducted by one researcher. After screening the titles and abstracts, 37 articles in English and 92 articles in Chinese were included for full-text review. After full-text review, nine English and 29 Chinese articles were excluded because they did not report any information on measurement and survey administration. This resulted in a total of 28 articles in English and 63 articles in Chinese that were included in the final analysis. Among them, nine articles include two sub-studies each. One article includes three sub-studies. Therefore, 102 studies were included in the current analysis. a total of 81 studies focus on community health centers, 17 studies - on township health centers and four studies-on village clinics. The description of each study is provided in Supplement 2 and Supplement 3.

\subsection{Data Extraction and Analysis}

A data extraction form in Excel was developed to collect the following information: author, published date, the year when the study was conducted, study setting, domains measuring PHC, items measuring PHC, response options and survey administration methods. Due to the variations in measurements and administration methods between studies, a descriptive reporting approach was used.

\section{Results}

A total of 102 studies were included for data analysis. More than $80 \%(84)$ of the studies were published after 2009 when China launched its national health reform. Most studies were conducted in eastern (more developed) provinces in China. Guangdong (29), Shanghai (9) and Shandong (8) contributed to nearly half of the studies.

\subsection{Patient Experience Measurements Adapted from Other Instruments}

The measurements adapted from the instruments developed in other countries were used in over one-third (37 of 102) of the studies (Table 1). The PCAT and the WHO Health System Responsiveness Survey were the two instruments most often used in China.

Table 1. Patient experience measurements of primary health care in the 102 studies.

\begin{tabular}{lc}
\hline \multicolumn{1}{c}{ Instrument } & No. of Studies \\
\hline Primary Care Assessment Tool (PCAT) & 18 \\
World Health Organization Health System Responsiveness Survey & 12 \\
Patient Assessment of Chronic Illness Care (PACIC) & 2 \\
Questionnaire of Continuity between Care Levels (CCAENA) & 1 \\
SERVQUAL & 2 \\
Australia patient satisfaction questionnaire & 1 \\
EUROPEP & 1 \\
Self-developed indicators by the authors & 65 \\
Total & 102 \\
\hline
\end{tabular}

The original PCAT developed by Barbara Starfield at the Johns Hopkins Primary Care Policy Center is the most widely used instrument in China, including Guangdong [28-38], Shanghai [28,33,39], Hunan [40] and Tibet [41]. The original English PCAT adult version includes seven domains: First Contact (accessibility and utilization), Continuity, Coordination (information and referral systems), Comprehensiveness (service availability and service provided), Community Orientation, Family Centeredness and Cultural Competency. The response options are a four-point Likert-type 
response scale where $1=$ definitely not, $2=$ probably not, $3=$ probably, $4=$ definitely and an additional option $9=$ not sure/do not know [24].

There are various Chinese versions of PCAT. Among 18 PCAT studies, 12 included all seven domains [29,33-38,41] and the remaining six used a subset [28,30,32,39,40,42]. For example, Community Orientation and Family Centeredness were not included in four studies [28,30,39,42] and Cultural Competency was not included in six studies [28,30,32,39,40,42]. Most studies followed the original four-point Likert-type response scale with the same wording but one study changed the wording of the response scale to $1=$ never; $2=$ sometimes; $3=$ often; and $4=$ always [30]. All PCAT studies included four of the seven domains (First Contact, Continuity, Coordination and Comprehensiveness), which correspond to Starfield's "core domains" [24]. Although Comprehensiveness was included in all studies, the items in each study varied [24,40,43].

The Health System Responsiveness Survey was developed by the WHO to measure the users' interaction with health services in eight domains: Dignity, Autonomy, Confidentiality, Communication, Prompt Attention, Quality of Basic Amenities, Social Support and Choice of health care providers. Questions measuring health system responsiveness cover ambulatory (22 items) and inpatient (11 items) visits. All questions used similarly ordered four-point (always, usually, sometimes, never) or five-point (mainly: very good, good, moderate, bad, very bad) Likert response options [23]. Among the 12 studies using this survey in China, only six studies included all eight domains [44-49]. Social Support was not included in five studies [50-54], Quality of Basic Amenities was not included in three studies $[50,54,55]$ and Choice of Providers was not included in three studies $[50,51,54]$. Most studies used the response scale suggested by the WHO, with just two studies not doing so [48,49]. However, no studies reported the psychometric properties of measurements.

\subsection{Patient Experience Measurements Developed by Authors Themselves}

Two-thirds (65 of 102) of the studies used measurements developed by the authors themselves. Most did not report the development process for these measurements. The frequency of PHC aspects, number of items and response options included in these measurements are summarized in Tables 2 and 3.

Table 2. The top 20 most frequent evaluated primary health care aspects in the 65 studies with self-developed measurements.

\begin{tabular}{llll}
\hline \multicolumn{1}{c}{ Aspects of Primary Health Care } & No. of Studies & $\begin{array}{c}\text { Aspects of Primary } \\
\text { Health Care }\end{array}$ & No. of Studies \\
\hline $\begin{array}{l}\text { Service attitude of health } \\
\text { professionals }\end{array}$ & 60 & Treatment outcome & 17 \\
Medical charge and cost & 53 & Privacy protection & 16 \\
Physical environment & 51 & Procedures of visit & 11 \\
Technical skill of health & 44 & Types of drugs & 10 \\
professionals & 43 & Respect & 8 \\
Medical equipment & 37 & Length of consultation & 8 \\
Convenience & 36 & Shared decision making & 6 \\
Waiting time & 29 & Whole person care & 5 \\
Doctors' explanation & 27 & Appropriate treatment & 5 \\
Overall rating & 21 & Trust & 5 \\
Range of services & & & \\
\hline
\end{tabular}


Table 3. Number of items and response scales in the 65 studies with self-developed measurements.

\begin{tabular}{cc}
\hline Number of Items & No. of Studies \\
\hline$<5$ & 5 \\
$5-10$ & 37 \\
$11-15$ & 16 \\
$16-20$ & 5 \\
$21-30$ & 2 \\
$>30$ & 1 \\
\hline Response scales \\
5-point Likert scale & 50 \\
3-point Likert scale & 5 \\
4-point Likert scale & 4 \\
6-point Likert scale & 3 \\
Not reported & 3 \\
\hline
\end{tabular}

More than 40 care aspects were evaluated in the 65 studies. The care aspects most frequently evaluated, in decreasing order, were: service attitude of health professionals $(92 \%)$; medical cost $(82 \%)$; physical environment (78\%); technical skill of health professionals (68\%); and medical equipment $(66 \%)$. Convenience and waiting times were evaluated in more than $50 \%$ of the studies. There are fewer studies that include interpersonal care aspects, such as privacy protection (25\%), respect $(12 \%)$, shared decision making ( $9 \%$ ) and the doctor's listening skills and patience $(6 \%)$.

The number of items reported in the studies ranged from 3 to 35, with the majority ranging from 5 to 15 . a five-point-Likert response scale was used most often (50 out of 65 ) although some studies used three, four or six response options. The wording of five-point response options also varied. For example, some studies used "always, usually, sometimes, occasionally, never" or "completely agree, agree, not sure, disagree, completely disagree". Other studies used "very good, good, neutral, bad, very bad" or "very satisfied, satisfied, neutral, dissatisfied, very dissatisfied". Depending on the types of questions (declarative or evaluative) measuring patient perception, further research could explore appropriate evaluative language and response scales among Chinese people.

Only six out of the 65 studies reported the psychometric properties of measurements [56-61]. Four studies reported good validity and reliability based on the results of Cronbach's $\alpha$ and principle component analyses [56-58,61]. One study briefly reported good reliability and unacceptable validity without reporting any detail about data analysis [59]. One study only tested face and content validity through a pilot study with 30 respondents [60].

\subsection{Survey Implementation Approach}

The on-site survey was used by 99 studies while only three out of the 102 studies used a telephone survey. For the location of the on-site survey, the exit of primary care institutions is the most common place and was used by $63 \%$ of the studies. For the administration of the on-site survey, a face-to-face interview was reported by 29 studies and self-administration was reported by 14 studies, while this information was missing in the remaining 56 studies (Table 4). 
Table 4. Survey administration methods in the 102 studies.

\begin{tabular}{cc}
\hline Survey Method & No. of Studies \\
\hline On-site survey & 99 \\
Place of survey & 64 \\
Primary care institutions & 28 \\
Community or patient' home & 7 \\
Not reported & \\
Administration method & 29 \\
Face-to-Face interview & 14 \\
Self-administration & 56 \\
Not reported & 3 \\
Telephone survey & \\
\hline
\end{tabular}

\section{Discussion}

Based on our previous research, we captured two major points relating to patient evaluation studies of PHC in China: the inconsistency of survey instruments and implementation approaches. Through a thorough discussion with PHC researchers in China and Canada, we agreed that a narrative review was an efficient approach to produce an overall picture about what measurements have been used and how they have been implemented among the patient evaluation studies of PHC in China. The advantage of this approach is that it offers breadth of literature coverage and the flexibility to deal with evolving knowledge and concepts, without requiring more time and resources to prepare and update the records as in a systematic review [62]. To include as many relevant publications as possible, we identified search terms in Chinese and English using a brainstorming technique within our research team, and developed the search strategy through an iterative approach (trying different wording of search terms and different combinations). Finally, we applied our search strategy in both PubMed and CNKI, which are the main databases that include publications about Chinese health services in English and Chinese, respectively. Although there is a small possibility that some relevant publications were missed in our search, we are confident that the results portray a comprehensive picture of patient evaluation studies of PHC in China.

Through the analysis of 102 patient evaluation studies of PHC in China, we found that most studies used author-developed instruments with commonly used five-point Likert response options and many used Chinese translations of the instruments developed in other countries. Furthermore, most author-developed instruments measure the structural dimensions of PHC, and most measures focus on satisfaction to rate subjective perception rather than on care experience to report objective problems.

\subsection{Issues of Measurements Adapted from Other Countries}

The studies included in our review used a similar approach to adapting instruments but the results varied even in the same context. This calls for national collaboration to address these issues. For example, three studies reported the adaptation process and validation results of PCAT in China $[40,43,63]$. Each used the following process: forward-backward translation; consensus by an expert panel to identify the appropriateness of items and domains; and a pilot test to improve item wording. However, the three Chinese versions vary, particularly in item wording. Even for the same item in the original PCAT, there were variations in some of the Chinese translations. These variations lead to varied findings of the psychometric properties of this instrument. For example, a validation study in Guangdong confirmed the construct factors embedded in the original PCAT [63]. However, another study in the same province using the same validation technique suggests that some domains should be removed, including Family Centeredness, Community Orientation and Cultural Competence as well as two items measuring First Contact and Coordination [43]. The psychometric analysis in the province of Hunan also showed that the factor constructs did not fit well with the underlying theoretical constructs in the original PCAT [40]. For each domain of primary 
care, First Contact fails to meet optimal psychometric standards of internal consistency in two studies in China. These studies found that Cronbach's $\alpha$ was only 0.38 [43] and 0.48 [40] for First Contact-Utilization, respectively. The internal consistency of Comprehensiveness also showed inconsistent results between different studies $[40,43,63]$.

The principles of First Contact, Continuity, Coordination and Comprehensiveness that are included in PCAT are recognized and shared internationally. However, service delivery and financing systems vary significantly between countries. The tools developed in one context may not be appropriate in another. For the same domain of primary care, the patients in different countries may have a different understanding and expectations. For example, First Contact items from the original PCAT may not be appropriate in countries with a different health system organization and patient expectations. Making appointments in advance and gatekeeping by primary care workers may not be applicable in some countries [64,65]. Geographical accessibility is a major constraint for local people to get to health care services in rural and remote areas, but it was not addressed in the original PCAT. Similar issues are likely to pertain to Comprehensiveness and Coordination with specialists.

\subsection{Issues of Measurements Developed by Authors}

Most author-developed measures focus on the structural dimensions of PHC, such as the physical environment, medical equipment and convenience (distance from home to facility). The interest in predominantly evaluating the structural dimensions is based on the assumption that adequately trained doctors and nurses with access to infrastructure (such as well-equipped facilities and medicines) will be sufficient for guaranteeing adequate quality [66]. However, emerging evidence suggests that this understanding may be incorrect. For example, a cross-sectional study of 4,300 facilities in eight countries demonstrated that the structural input characteristics (amenities, equipment and medications) of health facilities are poorly correlated with the provision of evidence-based care (providers' adherence to evidence-based care guidelines) [67]. Furthermore, if user perceptions in patient surveys closely reflect the observable infrastructural facilities, questions related to these perceptions would not add to what could be learned from direct observation using facility surveys [68]. These observations highlight the inappropriateness of evaluating the structural aspects of PHC from a user perspective.

Although the technical skills of doctors are also often evaluated by patients in China, there is a weak correlation between the patient-perceived technical quality of care and technical quality measures extracted from medical records [69]. However, strong correlations were identified between the patient-perceived technical quality and their assessment of doctors' interpersonal communication skills and trustworthiness [69]. Few patients have sufficient knowledge about their own illness or about possible treatment options to make an informed judgement about the technical quality of care [70]. When patients are asked about technical quality, they are more likely to make judgements based on the care aspects that they feel they are able to judge. Experts claim that clinician reports and medical chart reviews are better approaches to evaluating technical quality of care [71].

\subsection{Satisfaction and Care Experience}

Most patient survey measures of PHC in China focus on satisfaction to rate subjective perception rather than on patients' care experience to report objective problems. In addition, there is increasing interest in patient satisfaction studies in hospital settings in China [71-75]. In developed countries, the rising consumerism in the 1970s and 1980s has led to an increased emphasis on patient perspectives [76]. The motivation for early patient surveys was to keep patients "happy" or "satisfied" rather than ask about what did or did not happen. Although extensive studies were conducted on patient satisfaction assessment, many of them did not explicitly elicit quality information from patients. Since the 1990s, it became clear that as a tool for quality improvement, the patient satisfaction survey was neither very sensitive nor very useful $[76,77]$. There is agreement that the definitive conceptualization of satisfaction with health care has still not been achieved and that understanding the process by which a patient becomes satisfied or dissatisfied 
remains unanswered [78]. Subsequently, patient surveys shifted towards reporting patient-reported care experience, which is now considered to provide more specific information to guide quality improvement compared to satisfaction measures [19,79-81]. The evolution of patient surveys from assessing satisfaction to focusing on care experience in developed countries suggests that apart from the increasing interest in patient satisfaction, patient care experience studies should also gain more attention in China.

\subsection{Survey Implementation}

The patient exit survey in primary care institutions is the most commonly used survey implementation method in China. The popularity of the patient exit survey is due to its operational efficiency as it is more convenient to identify patients at clinics than through population-based surveys [82]. However, there are also arguments about the patient exit surveys that respondents in many cases do not openly report about negative experiences when they are within the premises of health facilities [68]. Another potential problem relates to the sampling approach. In almost all studies using the patient exit survey, the interviewer selected the next patient exiting the clinic after completing an interview. However, recent evidence shows that this sampling method yields a biased sample as patients who spend a longer time with the clinician are overrepresented. This bias can be removed by selecting the next patient who enters rather than exits the consultation room, which is operationally more efficient than alternative methods (systematic and simple random sampling) in most PHC settings [82]. In addition, most studies included in this review did not report clear information on sampling frames and patient recruitment procedures.

The two most popular survey administration methods in patient exit surveys in China are: face-to-face verbal interviews using paper and pencil; and the traditional paper and self-administration method involving handing paper questionnaires to people in person and asking them to complete them by hand and return them to the researcher. Some studies used both methods. Face-to-face interviews have the advantage of a high response rate and low cognitive burden for the respondents although this method leads to a high social desirability bias and interviewer bias [83]. The visual and written method of self-administration has the advantage of a low social desirability bias and high willingness to disclose sensitive information but places high cognitive burden on respondents, especially the demand for literacy [83]. Besides, the characteristics of these different survey administration modes may also influence participants' response to the instruments, which needs to be examined further in the context of China.

\section{Conclusions and Practice Implication}

The patient experience measurements and survey implementation approaches are two major issues in patient evaluation studies of PHC in China. Most studies evaluate the structural dimensions of PHC, of which patients are not the best evaluators. Various wordings and categories of response options are used but it is unclear which one is optimal among Chinese people. Many studies do not report a detailed sampling approach or patient recruitment procedures and the effect of different survey administration methods on participants' responses is unclear.

The lack of consistency in survey instruments and administration methods indicates that more coordinated efforts are needed in order to develop valid instruments to evaluate patient perceptions of PHC performance in China. This study is only the first step to map out the current situation and propose future direction towards developing Chinese value-based patient experience measurements. As a starting point, explicit information about what matters most to patients in China should be investigated. Patient experience measurements should reflect patients' needs and preferences in their cultural and health system contexts. Patient preferences or priorities have been studied extensively in Europe and North America. These efforts consistently demonstrate that in addition to clinical competency or technical quality, interpersonal care aspects, such as interpersonal communication, shared decision-making, respectfulness and relational continuity, are also very 
important for patients [84-91]. However, these health care aspects, their operational definitions and subsequent measures have all been developed in western countries with PHC-based health systems, which may not be applicable in other countries. Foundational work is needed to identify patient priorities in China through a strong collaboration among different stakeholders, especially with patients, caregivers and family members. This work could be performed through qualitative research using narrative-based analysis, followed by quantitative research using a discrete choice experiment. This work would result in consensus on which care aspects of PHC could be measured by patients.

Subsequently, the operational definitions and optimal response scales should be explored and identified. For each PHC care aspect prioritized by patients, we need to capture the measurable terms or phrases that they use when reporting their care experience. We also need to capture the evaluative language and categories that they use when they make judgement of "good" or "bad" health care. This type of work could generate the elements included in each PHC care aspect and the optimal response scale among Chinese patients, which will guide the selection of items and survey development. Based on these achievements, a research agenda of developing patient experience measurements could be envisioned. In general, this includes setting up a research team, selecting the domains and items, consensus process around finalizing the initial survey, pilot testing and refinement, examination of psychometric properties and knowledge translation. At the same time, a standardized survey implementation strategy could be developed, including determining the sample size for each institution, outlining the sampling approach, data collection approach, data entry and management, data analysis format and guidelines on data reporting.

As China is moving towards building a people-centered integrated health system, measuring patient experience is an important approach to better understand patients' needs and preferences and to ensure that people-centered care is delivered. Action plans are needed in order to promote the development of a patient experience measurement and the application of patient experience information. First, a national patient experience measurement strategy could be developed, which might be incorporated into the functions of the National Medical Service Management Center. This national strategy would aim to coordinate all efforts to measure patient experience, which would allow the government and health care providers to produce compelling data on which decisions can be based. The UK and the USA are world leaders in this field. Supervised by Care Quality Commission (CQC), England's health care regulator, national patient experience surveys are conducted annually since 1998 through the National Health Service's (NHS) Patient Survey Program. In the USA, patient experience surveys are mainly conducted through the Consumer Assessment of Healthcare Providers and Systems (CAHPS) program, which was established in 1995 by the Agency for Healthcare Research and Quality (AHRQ), the government agency responsible for health care quality and research. Recently, Canada has also initiated the process of developing a federal and provincial strategy for patient experience measurement. Similar work could be conducted in China through strong collaboration between health authorities, care providers and researchers, while considering the experiences from the above-mentioned countries.

Second, more clarity is required around what information health authorities and health care providers need from patient experience surveys, including the format and how this information will be used by them in health policy making and quality improvement. International experiences have shown that managers and clinicians often struggle to link patient experience data to concrete transformations that could lead to an improved care experience [92]. These observations highlight the importance of involving local health authorities and health care providers in the development and implementation of patient experience surveys. Furthermore, exemplary primary care institutions with high patient experience performance should be selected as a benchmark in China. However, the link between organizational structure, management activities and patient experience performance is understudied. Further studies from leadership and change management perspectives at the health care organization level may deepen our understanding. 
Third, an effective public reporting program may also be established in order to inform patients of the care experience performance of different providers to guide their health care seeking behavior. Recognizing the value of transparency and accountability, publicly released performance information is not only viewed as a fundamental patient right but is also essential for improving the functioning of health care markets. There is evidence that consumers would use reports to support their decision making if the information was better designed and more relevant [93]. As China is expanding the family doctor contract service model, which aims to build a gatekeeper role of primary care clinics based on a long-term therapeutic relationship between family doctors and patients, publicly released performance information on family doctors may guide patients' choice of their family doctor and facilitate the building of a longitudinal relationship. Based on the lessons learned from public reporting programs in other countries, such as low patient awareness of the existence of public reports, sub-optimal patient engagement in report development, information complexity and patients' difficulty in processing numbers and abstract ideas, China could develop some innovative public reporting programs to target and deliver reports to Chinese patients.

Supplementary Materials: The following are available online at http:/ /www.mdpi.com/1660-4601/16/6/926/s1, Supplement 1: Search Strategy, Supplement 2: Patient evaluation studies published in English from PubMed, Supplement 3: Patient evaluation studies published in Chinese from China National Knowledge Infrastructure.

Author Contributions: Conceptualization, W.W., J.H. and X.L.; Methodology, W.W. and X.L.; Formal Analysis, W.W.; Writing - Original Draft Preparation, W.W., J.H., E.(K.)L., X.L.; Writing—Review \& Editing, W.W., J.H., E.(K.)L., X.L. All authors have approved the submitted version.

Funding: This research received no external funding.

Acknowledgments: Wenhua Wang was supported by Steinberg Global Health Postdoctoral Fellowship, McGill University, Canada.

Conflicts of Interest: The authors declare no conflict of interest.

\section{References}

1. Li, X.; Lu, J.; Hu, S.; Cheng, K.K.; De Maeseneer, J.; Meng, Q.; Mossialos, E.; Xu, D.R.; Yip, W.; Zhang, H.; et al. The primary health-care system in China. Lancet 2017, 390, 2584-2594. [CrossRef]

2. Meng, Q.; Yang, H.; Chen, W.; Sun, Q.; Liu, X. Health Systems in Transition. In People's Republic of China Health System Review; WHO Regional Office for the Western Pacific: Manila, Philippines, 2015.

3. Yip, W.; Hsiao, W. Harnessing the privatization of China's fragmented health-care delivery. Lancet 2014, 384, 805-818. [CrossRef]

4. Yip, W.C.; Hsiao, W.C.; Chen, W.; Hu, S.; Ma, J.; Maynard, A. Early appraisal of China's huge and complex health-care reforms. Lancet 2012, 379, 833-842. [CrossRef]

5. Blumenthal, D.; Hsiao, W. Privatization and its discontents-The evolving Chinese health care system. N. Engl. J. Med. 2005, 353, 1165-1170. [CrossRef] [PubMed]

6. Tang, S.; Brixi, H.; Bekedam, H. Advancing universal coverage of healthcare in China: Translating political will into policy and practice. Int. J. Health Plan. Manag. 2014, 29, 160-174. [CrossRef] [PubMed]

7. Yip, W.C.; Hsiao, W.; Meng, Q.; Chen, W.; Sun, X. Realignment of incentives for health-care providers in China. Lancet 2010, 375, 1120-1130. [CrossRef]

8. Liu, Y.; Hsiao, W.C.; Eggleston, K. Equity in health and health care: The Chinese experience. Soc. Sci. Med. 1999, 49, 1349-1356. [CrossRef]

9. State Council of the People's Republic of China. Opinions on Deepening the Health Care Reform. 2009. Available online: http:/ /www.gov.cn/jrzg/2009-04/06/content_1278721.htm (accessed on 24 February 2018)In Chinese.

10. World Health Organization. WHO Global Strategy on People-Centred and Integrated Health Services: Interim Report; World Health Organization: Geneva, Switzerland, 2015; p. 47.

11. World Bank. Deepening Health Reform in China: Building High-Quality and Value-Based Service Delivery-Policy Summary; World Bank Group: Washington, DC, USA, 2016.

12. Doyle, C.; Lennox, L.; Bell, D. a systematic review of evidence on the links between patient experience and clinical safety and effectiveness. BMJ Open 2013, 3, e001570. [CrossRef] [PubMed] 
13. Wong, S.T.; Black, C.; Cutler, F.; Brooke, R.; Haggerty, J.L.; Levesque, J.F. Patient-reported confidence in primary healthcare: Are there disparities by ethnicity or language? BMJ Open 2014, 4, e003884. [CrossRef]

14. Haggerty, J.; Burge, F.; Levesque, J.F.; Gass, D.; Pineault, R.; Beaulieu, M.D.; Santor, D. Operational definitions of attributes of primary health care: Consensus among Canadian experts. Ann. Fam. Med. 2007, 5, 336-344. [CrossRef] [PubMed]

15. Anhang Price, R.; Elliott, M.N.; Zaslavsky, A.M.; Hays, R.D.; Lehrman, W.G.; Rybowski, L.; Edgman-Levitan, S.; Cleary, P.D. Examining the role of patient experience surveys in measuring health care quality. Med. Care Res. Rev. 2014, 71, 522-554. [CrossRef] [PubMed]

16. Stewart, M.; Brown, J.B.; Donner, A.; McWhinney, I.R.; Oates, J.; Weston, W.W.; Jordan, J. The impact of patient-centered care on outcomes. J. Fam. Pract. 2000, 49, 796-804. [PubMed]

17. Hudon, C.; Fortin, M.; Haggerty, J.L.; Lambert, M.; Poitras, M.E. Measuring patients' perceptions of patient-centered care: a systematic review of tools for family medicine. Ann. Fam. Med. 2011, 9, 155-164. [CrossRef] [PubMed]

18. Little, P.; Everitt, H.; Williamson, I.; Warner, G.; Moore, M.; Gould, C.; Ferrier, K.; Payne, S. Observational study of effect of patient centredness and positive approach on outcomes of general practice consultations. BMJ 2001, 323, 908-911. [CrossRef] [PubMed]

19. Anhang Price, R.; Elliott, M.N.; Cleary, P.D.; Zaslavsky, A.M.; Hays, R.D. Should health care providers be accountable for patients' care experiences? J. Gen. Intern. Med. 2015, 30, 253-256. [CrossRef] [PubMed]

20. Safran, D.G.; Kosinski, M.; Tarlov, A.R.; Rogers, W.H.; Taira, D.H.; Lieberman, N.; Ware, J.E. The primary care assessment survey: Tests of data quality and measurement performance. Med. Care 1998, 36, 728-739. [CrossRef] [PubMed]

21. Dyer, N.; Sorra, J.S.; Smith, S.A.; Cleary, P.D.; Hays, R.D. Psychometric properties of the consumer assessment of healthcare providers and systems (CAHPS(R)) clinician and group adult visit survey. Med. Care 2012, 50 (Suppl. S28-S34). [CrossRef] [PubMed]

22. Scholle, S.H.; Vuong, O.; Ding, L.; Fry, S.; Gallagher, P.; Brown, J.A.; Hays, R.D.; Cleary, P.D. Development of and field test results for the CAHPS PCMH survey. Med. Care 2012, 50 (Suppl. S2-S10). [CrossRef]

23. Valentine, N.B.; Bonsel, G.J.; Murray, C.J. Measuring quality of health care from the user's perspective in 41 countries: Psychometric properties of WHO's questions on health systems responsiveness. Qual. Life Res. 2007, 16, 1107-1125. [CrossRef] [PubMed]

24. Shi, L.; Starfield, B.; Xu, J. Validating the adult primary care assessment tool. J. Fam. Pract. 2001, 50, 161.

25. Ramsay, J.; Campbell, J.L.; Schroter, S.; Green, J.; Roland, M. The general practice assessment survey (GPAS): Tests of data quality and measurement properties. Fam. Pract. 2000, 17, 372-379. [CrossRef]

26. Haggerty, J.L.; Beaulieu, C.; Lawson, B.; Santor, D.A.; Fournier, M.; Burge, F. What patients tell us about primary healthcare evaluation instruments: Response formats, bad questions and missing pieces. Healthc. Policy 2011, 7, 66-78. [CrossRef] [PubMed]

27. Drake, K.M.; Hargraves, J.L.; Lloyd, S.; Gallagher, P.M.; Cleary, P.D. The effect of response scale, administration mode, and format on responses to the CAHPS Clinician and Group survey. Health Serv. Res. 2014, 49, 1387-1399. [CrossRef]

28. Wei, X.; Li, H.; Yang, N.; Wong, S.Y.; Chong, M.C.; Shi, L.; Wong, M.C.; Xu, J.; Zhang, D.; Tang, J.; et al. Changes in the perceived quality of primary care in Shanghai and Shenzhen, China: a difference-in-difference analysis. Bull. World Health Organ. 2015, 93, 407-416. [CrossRef] [PubMed]

29. Feng, S.; Shi, L.; Zeng, J.; Chen, W.; Ling, L. Comparison of primary care experiences in village clinics with different ownership models in Guangdong Province, China. PLoS ONE 2017, 12, e0169241. [CrossRef] [PubMed]

30. Kuang, L.; Liang, Y.; Mei, J.; Zhao, J.; Wang, Y.; Liang, H.; Shi, L. Family practice and the quality of primary care: a study of Chinese patients in Guangdong Province. Fam. Pract. 2015, 32, 557-563. [CrossRef]

31. Zou, Y.; Zhang, X.; Hao, Y.; Shi, L.; Hu, R. General practitioners versus other physicians in the quality of primary care: a cross-sectional study in Guangdong Province, China. BMC Fam. Pract. 2015, 16, 134. [CrossRef] [PubMed]

32. Wang, H.H.; Wong, S.Y.; Wong, M.C.; Wei, X.L.; Wang, J.J.; Li, D.K.; Tang, J.L.; Gao, G.Y.; Griffiths, S.M. Patients' experiences in different models of community health centers in southern China. Ann. Fam. Med. 2013, 11, 517-526. [CrossRef] 
33. Wei, X.; Yin, J.; Wong, S.Y.; Griffiths, S.M.; Zou, G.; Shi, L. Private ownership of primary care providers associated with patient perceived quality of care: a comparative cross-sectional survey in three big Chinese cities. Medicine 2017, 96, e5755. [CrossRef]

34. Zeng, J.; Shi, L.; Zou, X.; Chen, W.; Ling, L. Rural-to-urban migrants' experiences with primary care under different types of medical institutions in Guangzhou, China. PLOS ONE 2015, 10, e0140922. [CrossRef]

35. Hu, R.; Liao, Y.; Du, Z.; Hao, Y.; Liang, H.; Shi, L. Types of health care facilities and the quality of primary care: a study of characteristics and experiences of Chinese patients in Guangdong Province, China. BMC Health Serv. Res. 2016, 16, 335. [CrossRef] [PubMed]

36. Du, Z.; Liao, Y.; Chen, C.C.; Hao, Y.; Hu, R. Usual source of care and the quality of primary care: a survey of patients in Guangdong province, China. Int. J. Equity Health 2015, 14, 60. [CrossRef]

37. Lin, Y.; Zhang, S.; Yu, X.; Zhang, C. The effect of community health service quality on the management of hypertension based on PCAT scale. Chin. J. Soc. Med. 2017, 34, 369-371. (In Chinese)

38. Liu, X.; Gao, Q.; You, H.; Fu, M.; Yu, L.; Liang, X.; Chen, S. Impacts of the level of hospitals owning community health service institutions on quality of primary care experiences. Med. Soc. 2016, 29, 17-19. (In Chinese)

39. Li, H.; Wei, X.; Wong, M.C.; Wong, S.Y.; Yang, N.; Griffiths, S.M. a cross-sectional comparison of perceived quality of primary care by hypertensive patients in Shanghai and Shenzhen, China. Medicine 2015, 94, e1388. [CrossRef] [PubMed]

40. Yang, H.; Shi, L.; Lebrun, L.A.; Zhou, X.; Liu, J.; Wang, H. Development of the Chinese primary care assessment tool: Data quality and measurement properties. Int. J. Qual. Health Care 2013, 25, 92-105. [CrossRef] [PubMed]

41. Wang, W.; Shi, L.; Yin, A.; Mao, Z.; Maitland, E.; Nicholas, S.; Liu, X. Primary care quality among different health care structures in Tibet, China. Biomed. Res. Int. 2015, 2015, 206709. [CrossRef]

42. Shi, L.; Lee, D.C.; Liang, H.; Zhang, L.; Makinen, M.; Blanchet, N.; Kidane, R.; Lindelow, M.; Wang, H.; Wu, S. Community health centers and primary care access and quality for chronically-ill patients-A case-comparison study of urban Guangdong Province, China. Int. J. Equity Health 2015, 14, 90. [CrossRef]

43. Mei, J.; Liang, Y.; Shi, L.; Zhao, J.; Wang, Y.; Kuang, L. The development and validation of a rapid assessment tool of primary care in China. Biomed. Res. Int. 2016, 2016, 6019603. [CrossRef]

44. Hui, W.; Yuchun, L.; Lin, L.; Yu, D.; Weidong, W. Evaluation of community health service institutions responsiveness in Henan Province: Key informant survey. Chin. J. Health Policy 2015, 8, 48-53. (In Chinese)

45. Qi, Z.; Qinglong, W.; Youshu, W.; Hongmei, C.; Cuili, C. Investigation of community health services responsiveness in Nantong city. Acta Academiae Medicinae Nantong 2009, 29, 259-262. (In Chinese)

46. Qilong, M.; Wenqiang, Y.; Dongmei, H.; Meng, M.; Dan, L. Study on patients' responsiveness community health service of three cities in Shangdong Province. Chin. Prim. Health Care 2009, 23, 26-28. (In Chinese)

47. Xuelian, W.; Zhenquan, Z.; Honglian, W.; Qiaoyu, J. Fuzzy synthetic discrimination on the responsiveness of community health service in Fuzhou. Chin. Prim. Health Care 2008, 22, 18-20. (In Chinese)

48. Bing, L.; Xianghua, G.; Fang, W.; Ligao, J.; Bing, Y.; Zuxun, L. Evaluation on community health service respons in Shiyan City. Chin. Prim. Health Care 2007, 21, 33-35. (In Chinese)

49. Jing, Z.; Youhua, Y.; Chen, L. Analysis on responsiveness assessment of community health service in Zhabei District of Shanghai. Chin. Prim. Health Care 2007, 21, 28-30. (In Chinese)

50. Yun, W. Study on the Index of Performance Evaluation of the Community Health Service System at District Level. Master's Thesis, Huazhong University of Science \& Technology, Wuhan, China, 2008.

51. Sheng, W. Study on the Demand and Utilization to Community Health Service of Gongming Neighborhood in Shenzhen. Master's Thesis, Kunming Medical College, Kunming, China, 2007.

52. Wenqiang, Y. The Comprehensive Evaluation of Urban Community Health Services and Research on Sustainable Development Strategy. Ph.D. Thesis, Fudan University, Shangai, China, 2003.

53. Zhiming, P.; Zhenquan, Z.; Yongqian, L. Satisfaction and responsiveness of Fuzhou inhabitants to community health service. China Gen. Pract. 2009, 12, 1652-1653.

54. Wang, W.; Maitland, E.; Nicholas, S.; Loban, E.; Haggerty, J. Comparison of patient perceived primary care quality in public clinics, public hospitals and private clinics in rural China. Int. J. Equity Health 2017, 16, 176. [CrossRef] 
55. Dehua, Y.; Jinyi, L.; Yi, S.; Zuxun, L. Analysis on responsiveness assessment and influence factors of community health service in Shenzhen. China Gen. Pract. 2005, 8, 359-362.

56. Si, M. The survey on community residents' satisfaction with community health services: a case study in Zibo. Master's Thesis, Hebei Jingmao University, Baoding, China, 2015; pp. 23-24. (In Chinese)

57. Huang, W. The survey on residents' satisfaction of community health services in Guangzhou. Master's Thesis, Guangdong Pharmacy College, Guangzhou, China, 2012; pp. 5-6. (In Chinese)

58. Sun, S.; Fan, C.; Gong, X.; Xu, J.; Jin, W.; Liu, Y.; Yao, L. Empirical research on the evaluation index system of residents' satisfaction with community health services in Wuhan. Med. Soc. 2009, 22, 20-21. (In Chinese)

59. Yuan, J.; Liu, G.; Wang, P.; Meng, B.; Li, X. The survey and evaluation of resident satisfaction with community health services in Taiyuan. Chin. Remedies Clin. 2009, 9, 1184-1186.

60. Wu, D.; Lam, T.P.; Lam, K.F.; Zhou, X.D.; Sun, K.S. Public views towards community health and hospital-based outpatient services and their utilisation in Zhejiang, China: a mixed methods study. BMJ Open 2017, 7, e017611. [CrossRef] [PubMed]

61. Dib, H.H.; Sun, P.; Minmin, Z.; Wei, S.; Li, L. Evaluating community health centers in the City of Dalian, China: How satisfied are patients with the medical services provided and their health professionals? Health Place 2010, 16, 477-488. [CrossRef] [PubMed]

62. Byrne, J.A. Improving the peer review of narrative literature reviews. Res. Integr. Peer Rev. 2016, 1, 12. [CrossRef] [PubMed]

63. Wang, H.H.; Wong, S.Y.; Wong, M.C.; Wang, J.J.; Wei, X.L.; Li, D.K.; Tang, J.L.; Griffiths, S.M. Attributes of primary care in community health centres in China and implications for equitable care: a cross-sectional measurement of patients' experiences. QJM 2015, 108, 549-560. [CrossRef] [PubMed]

64. Van Weel, C.; Kassai, R. Expanding primary care in South and East Asia. BMJ 2017, 356, j634. [CrossRef]

65. Van Weel, C.; Kassai, R.; Tsoi, G.W.; Hwang, S.J.; Cho, K.; Wong, S.Y.; Phui-Nah, C.; Jiang, S.; Ii, M.; Goodyear-Smith, F. Evolving health policy for primary care in the Asia Pacific region. Br. J. Gen. Pract. 2016, 66, e451-e453. [CrossRef] [PubMed]

66. Jishnu Das Woskie, L.; Rajbhandari, R.; Abbasi, K.; Jha, A. Rethinking assumptions about delivery of healthcare: Implications for universal health coverage. BMJ 2018, 361, k1716.

67. Leslie, H.H.; Sun, Z.; Kruk, M.E. Association between infrastructure and observed quality of care in 4 healthcare services: a cross-sectional study of 4300 facilities in 8 countries. PLoS Med. 2017, 14, e1002464. [CrossRef] [PubMed]

68. Sah, D.C.; Kumar, Y. Client satisfaction exit interviews: Assessing quality of public health institutions through generated feedback. Vikalpa J. Decis. Mak. 2015, 40, 42-61. [CrossRef]

69. Rao, M.; Clarke, A.; Sanderson, C.; Hammersley, R. Patients' own assessments of quality of primary care compared with objective records based measures of technical quality of care: Cross sectional study. BMJ 2006, 333, 19. [CrossRef] [PubMed]

70. Chapple, A.; Campbell, S.; Rogers, A.; Roland, M. Users' understanding of medical knowledge in general practice. Soc. Sci. Med. 2002, 54, 1215-1224. [CrossRef]

71. Sun, J.; Hu, G.; Ma, J.; Chen, Y.; Wu, L.; Liu, Q.; Hu, J.; Livoti, C.; Jiang, Y.; Liu, Y. Consumer satisfaction with tertiary healthcare in China: Findings from the 2015 China National Patient Survey. Int. J. Qual Health Care 2017, 29, 213-221. [CrossRef] [PubMed]

72. Hu, Y.; Zhang, Z.; Xie, J.; Wang, G. The outpatient experience questionnaire of comprehensive public hospital in China: Development, validity and reliability. Int. J. Qual Health Care 2017, 29, 40-46. [CrossRef] [PubMed]

73. Bao, Y.; Fan, G.; Zou, D.; Wang, T.; Xue, D. Patient experience with outpatient encounters at public hospitals in Shanghai: Examining different aspects of physician services and implications of overcrowding. PLoS ONE 2017, 12, e0171684. [CrossRef] [PubMed]

74. Yu, W.; Li, M.; Xue, C.; Wang, J.; Liu, J.; Chen, H.; Zhang, L. Determinants and influencing mechanism of outpatient satisfaction: a survey on tertiary hospitals in the People's Republic of China. Patient Prefer. Adher. 2016, 10, 601-612.

75. Wei, J.; Shen, L.; Yang, H.B.; Qin, J.B.; Huang, W.; Zhang, J.J.; Gong, Q.Y.; Li, X.X.; Yang, T.B. Development and validation of a Chinese outpatient satisfaction questionnaire: Evidence from 46 public general hospitals and 5151 outpatients. Public Health 2015, 129, 1523-1529. [CrossRef] [PubMed]

76. Cleary, P.D. Evolving concepts of patient-centered care and the assessment of patient care experiences: Optimism and opposition. J. Health Polit. Policy Law 2016, 41, 675-696. [CrossRef] [PubMed] 
77. Delnoij, D.M. Measuring patient experiences in Europe: What can we learn from the experiences in the USA and England? Eur. J. Public Health 2009, 19, 354-356. [CrossRef] [PubMed]

78. Crow, R.; Gage, H.; Hampson, S.; Hart, J.; Kimber, A.; Storey, L.; Thomas, H. The measurement of satisfaction with healthcare: Implications for practice from a systematic review of the literature. Health Technol. Assess. 2002, 6, 1-244. [CrossRef] [PubMed]

79. Collins, K.; O'Cathain, A. The continuum of patient satisfaction-From satisfied to very satisfied. Soc. Sci. Med. 2003, 57, 2465-2470. [CrossRef]

80. Beatrice, D.F.; Thomas, C.P.; Biles, B. Grant making with an impact: the Picker/Commonwealth Patient-Centered Care Program. Health Aff (Millwood) 1998, 17, 236-244. [CrossRef] [PubMed]

81. Haggerty, J.L. Are measures of patient satisfaction hopelessly flawed? BMJ 2010, 341, c4783. [CrossRef] [PubMed]

82. Geldsetzer, P.; Fink, G.; Vaikath, M.; Barnighausen, T. Sampling for patient exit interviews: Assessment of methods using mathematical derivation and computer simulations. Health Serv. Res. 2018, 53, $256-272$. [CrossRef] [PubMed]

83. Bowling, A. Mode of questionnaire administration can have serious effects on data quality. J. Public Health 2005, 27, 281-291. [CrossRef] [PubMed]

84. Wensing, M.; Jung, H.P.; Mainz, J.; Olesen, F.; Grol, R. a systematic review of the literature on patient priorities for general practice care. Part 1: Description of the research domain. Soc. Sci. Med. 1998, 47, 1573-1588. [CrossRef]

85. Grol, R.; Wensing, M.; Mainz, J.; Ferreira, P.; Hearnshaw, H.; Hjortdahl, P.; Olesen, F.; Ribacke, M.; Spenser, T.; Szecsenyi, J. Patients' priorities with respect to general practice care: An international comparison. European Task Force on patient evaluations of general practice (EUROPEP). Fam. Pract. 1999, 16, 4-11. [CrossRef] [PubMed]

86. Jung, H.P.; Baerveldt, C.; Olesen, F.; Grol, R.; Wensing, M. Patient characteristics as predictors of primary health care preferences: a systematic literature analysis. Health Expect. 2003, 6, 160-181. [CrossRef]

87. Coulter, A. What do patients and the public want from primary care? BMJ 2005, 331, 1199-1201. [CrossRef] [PubMed]

88. Fung, C.H.; Elliott, M.N.; Hays, R.D.; Kahn, K.L.; Kanouse, D.E.; McGlynn, E.A.; Spranca, M.D.; Shekelle, P.G. Patients' preferences for technical versus interpersonal quality when selecting a primary care physician. Health Serv. Res. 2005, 40, 957-977. [CrossRef]

89. Groenewegen, P.P.; Kerssens, J.J.; Sixma, H.J.; van der Eijk, I.; Boerma, W.G. What is important in evaluating health care quality? An international comparison of user views. BMC Health Serv. Res. 2005, 5, 16. [CrossRef]

90. Wong, S.T.; Watson, D.E.; Young, E.; Regan, S. What do people think is important about primary healthcare? Healthc Policy 2008, 3, 89-104. [CrossRef] [PubMed]

91. Kleij, K.S.; Tangermann, U.; Amelung, V.E.; Krauth, C. Patients' preferences for primary health care-A systematic literature review of discrete choice experiments. BMC Health Serv. Res. 2017, 17, 476. [CrossRef] [PubMed]

92. Dubé-Linteau, A. Measuring Patient Experience through Surveys: From Concepts to Best Practices; Études et documents; Institut de la Statistique du Québec: Quebec, QC, Canada, 2017; p. 37.

93. Hussey, P.S.; Luft, H.S.; McNamara, P. Public reporting of provider performance at a crossroads in the United States: Summary of current barriers and recommendations on how to move forward introduction. Med. Care Res. Rev. 2014, 71, 5s-16s. [CrossRef] [PubMed]

(C) 2019 by the authors. Licensee MDPI, Basel, Switzerland. This article is an open access article distributed under the terms and conditions of the Creative Commons Attribution (CC BY) license (http:/ / creativecommons.org/licenses/by/4.0/). 